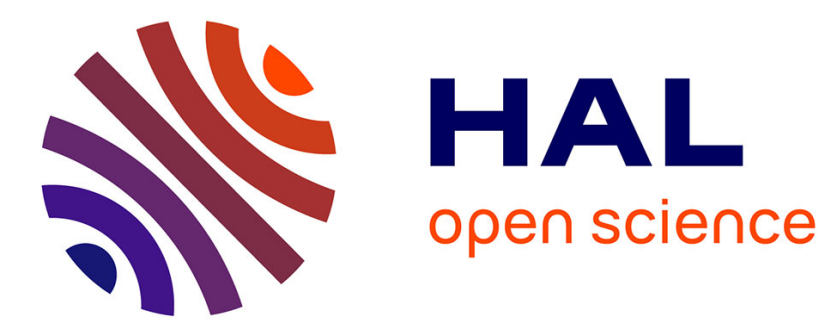

\title{
3D printing for construction based on a complex wall of polymer-foam and concrete
}

\author{
Benoit Furet, Philippe Poullain, Sébastien Garnier
}

\section{To cite this version:}

Benoit Furet, Philippe Poullain, Sébastien Garnier. 3D printing for construction based on a complex wall of polymer-foam and concrete. Additive Manufacturing, 2019, 28, pp.58 - 64 . 10.1016/j.addma.2019.04.002 . hal-03484504

\section{HAL Id: hal-03484504 https://hal.science/hal-03484504}

Submitted on 20 Dec 2021

HAL is a multi-disciplinary open access archive for the deposit and dissemination of scientific research documents, whether they are published or not. The documents may come from teaching and research institutions in France or abroad, or from public or private research centers.
L'archive ouverte pluridisciplinaire HAL, est destinée au dépôt et à la diffusion de documents scientifiques de niveau recherche, publiés ou non, émanant des établissements d'enseignement et de recherche français ou étrangers, des laboratoires publics ou privés.

\section{다)(1) $(5$}

Distributed under a Creative Commons Attribution - NonCommercial| 4.0 International 


\title{
Invited Research Article:
}

\section{D printing for construction based on a complex wall of polymer-foam and concrete.}

\author{
Benoit FURET ${ }^{1 *}$, Philippe POULLAIN², Sébastien GARNIER ${ }^{1}$ \\ 1 University of Nantes - LS2N UMR CNRS 6004 - IUT Nantes 2 Avenue Professeur Jean Rouxel - 44475 Carquefou - France \\ 2 University of Nantes - GeM UMR CNRS 6183 - IUT St Nazaire 58 rue Michel Ange - 44606 Saint Nazaire Cedex - France \\ * Corresponding authors. E-mail address: Benoit.Furet@univ-nantes.fr
}

\begin{abstract}
The objective of this paper is to present a new advanced Additive Manufacturing (AM) process for the construction of concrete structures: Batiprint $3 \mathrm{~d}^{\mathrm{TM}}$. The proposed advanced technology consists of creating a complex wall of 3D-printed materials using a mobile and polyarticulated robot: two polymer-foam printed walls are used to encase a subsequent third wall made of concrete. Once the walls were in place, the foam is maintained to provide both an internal and external insulation to the house without requiring thermal bridges. This technique of the complex wall with 3D-printed composite foam/concrete material is similar to the use of expansive-foam formwork (FW) filled by concrete or Insulated Concrete Forms (ICF) but in that case printed directly on site. By using 3D printing for the foam and extrusion of the concrete with the same robotic system, the technique creates jointly both the structure and thermal elements of the building. In the first part of this paper the composite foam/concrete 3D printing method and optimized process parameters are présented. Polyurethane (PU) foam has weak mechanical properties and the filling of the internal void with concrete can yield in high deformations and even failure of the FW, it is therefore necessary to control this phenomenon. For that, an experimental study has been conducted to determine a filling procedure capable of minimizing the deformations. The results show that spacers between the two foam walls can allow for wall heights of poured concrete up to $50 \mathrm{~cm}$. The problems solved, it was decided to experiment in full scale this new walls 3D printing method with the construction of Yhnova ${ }^{\mathrm{TM}}$, a real $95 \mathrm{~m}^{2}$ social housing. This technology Batiprint $3 \mathrm{~d}^{\mathrm{TM}}$ have been used, it is possible now to propose a synthesis of the impacts of this new advanced technology for construction.
\end{abstract}

Keywords: 3D printing, building, 3D printing for building, large-scale additive manufacturing process, foam 3D printing, new additive manufacturing process, polyurethane foam 


\section{Introduction:}

Currently, the construction industry needs to evolve similar to the way the manufacturing industry has done. Digital technologies with the BIM (Building Information Management or Building Information Model) and the VR (virtual reality) has started the construction evolution, a new technology of large scale additive manufacturing with 3D printing could be the next step. Additive manufacturing is defined by ASTM standards as a process of joining materials to make objects from 3D model data, usually layer upon layer [1]. Various manufacturing techniques can be used in this way such as binder jetting, direct energy deposition, extrusion of material, powder bed fusion etc.

The main benefits to the construction industry are :

- 3D printing allows the use of the right amount of material and offers the ability to create complex and customized shapes to users needs and the constraints of the field (topologic optimization [2]),

- The generation of complex part geometries can be produced at controlled costs $[3,4,5]$,

- The reduction of arduous human labor as automation and robotics assist workers [6, 7],

- Increased creativity for architects [7],

- Optimization of acoustic or thermal properties of the building [8].

In industrial manufacturing especially for the automobile, aeronautic or medical industries, evidence exists that additive manufacturing (AM) brings many benefits. In the case of building construction three advantages are identified: shorter building time, possibility of complex shape design, and alleviation of strenuous work [9].

Labonnote et al. [6] showed the evolution of large scale additive manufacturing for construction heavily influenced from the 1990's with Contour Crafting [10-11]. Several experiments of 3D printing for building around the world are presented in the following papers: WinSun [12], Loughborough University [13-14], D-Shape [15], 3D-Construction [16], XTreeE [8, 17], Apis Cor [18], , Batiprint3D [7, 19], Total Kustom [20], MIT [21], CyBe [22], BET Abram [23], 3D Printhuset [24].

Three categories of 3D printing for construction have been explored. The first is called binder jetting and corresponds to the projection of a lian (binder) at the locations provided by the CAD-model on a bed of sand that will agglomerate. Another thin layer of sand is then deposited, and the process repeats. At the end, it is necessary to remove the non-agglomerated sand [15]. The second category is called material extrusion in which a layer of mortar or clay is deposited and stiffens. The material must be sufficiently stiff to support the following upper layers [8-14, 17-20, 22-24]. The third technology of 3D printing for building is based on 3D printed formworks following the CAD-model and filled with mortar or concrete $\left[7,19\right.$ and 21]. Batiprint3 $\mathrm{D}^{\mathrm{TM}}$ differs from those stated above and is a new technology of 3D printing for buildings.

Batiprint3 $3 \mathrm{D}^{\mathrm{TM}}$ is based on a triple wall of 3D printed materials. Two polymer-foam printed walls are used to encase the third subsequent wall made of concrete. The polymer-foam is polyurethane and the process is a new technique of filled formwork, based on the deposition of polyurethane foam 
that expands and stiffens rapidly. The polymer material is deposited by a nozzle installed like an endeffector of a large robot and the trajectories are defined with the CAD-model. The deposition of two parallel walls of polyurethane (PU) foam creates a foam formwork (FW) into which the concrete is poured by the same robot. During the pouring of the concrete, the pressure exerted by the concrete on the FW can cause deformation. In order to assess the ability of the pouring process to limit the deformations at values lower than $5 \mathrm{~mm}$, experiments have been set up to study this challenge.

In the following sections, a short description of the Batiprint3 $\mathrm{D}^{\mathrm{TM}}$ technique, i.e. the material used, the robotics and the process, is presented. Then, the experimental device used to study the deformations of the FW and the results obtained is describe. Finally, the implementation of this filling procedure and construction is shown with the case of Yhnova ${ }^{\mathrm{TM}}$, a $95 \mathrm{~m}^{2}$ social dwelling built in Nantes using the Batiprint3 $\mathrm{D}^{\mathrm{TM}}$ technology.

\section{Technique and experimental device}

\subsection{The arrangement of the 3D printed wall}

The Batiprint3 $\mathrm{D}^{\mathrm{TM}}$ technique uses a complex wall with a self-compacting concrete in the middle of two walls of polyurethane (PU) foam (Figure 1). In order to comply with the technical recommendations regarding the strength of the structure described by the construction standards or regulations (Eurocode for example), the Batiprint $3 \mathrm{D}^{\mathrm{TM}}$ process makes it possible to print the foam and the concrete with the reinforcement steel metal.

On the outside, the foam is covered with a classic mortar coating to be protected from the weather, for the interior, the finish of the wall is provided by plasterboard.

The plasterboard allows to comply with all regulations regarding the fire resistance of homes. The process is started by the 3D printing operation of PU-Foam to create the FW layer by layer.

\subsection{Characteristics of PU foam}

By mixing together isocyanate and polyol, the polymer polyurethane foam is obtain. Mixing is performed in a dynamic mixer or a static one and the resulting compound is directly deposited onto the surface of the building slab. It takes only three seconds for the material to expand and about 45 seconds for the foam to obtain sufficient stiffness to support a new layer of foam.
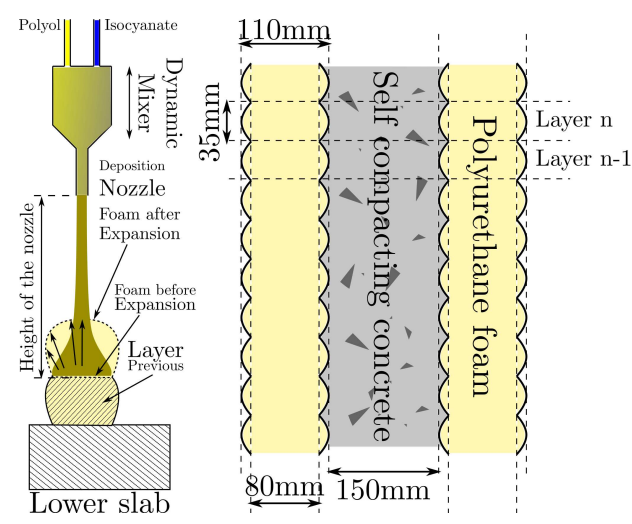

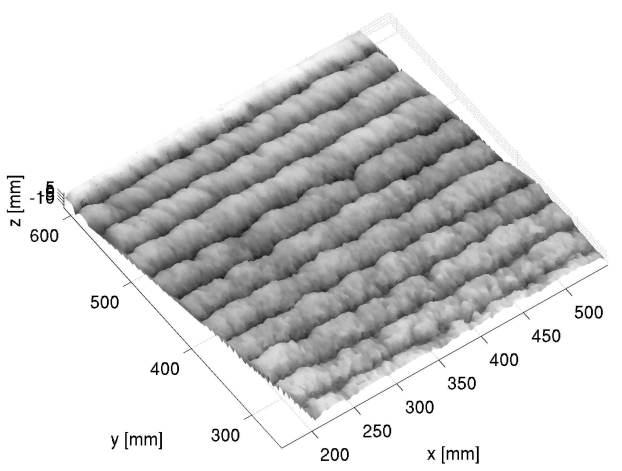

b) 3D scan of the polyurethane foam surface

Fig. 1

a)Complex wall cut

b) 3 scan of the polyurethane foam surface 
PU foam characteristics:

$>$ Density of the foam $=35 \mathrm{~kg} / \mathrm{m}^{3}$

$>$ Thermal conductivity $=0.027 \mathrm{~W} / \mathrm{m} . \mathrm{K}$

$>$ Young modulus $=7 \mathrm{MPa}$

$>$ Thermal resistance of the wall $(\mathrm{PU}$ foam + concrete $)=6.75 \mathrm{~m}^{2} . \mathrm{K} / \mathrm{W}$

By adjusting the flow rates of isocyanate and polyol, the height and the displacement speed of the nozzle, it can be possible to print a PU wall with a mean width of about 80 to $100 \mathrm{~mm}$ and the height of each layer is about $35 \mathrm{~mm}$. To obtain a thermal resistance of the wall (PU foam+concrete) at least equal to $6.75 \mathrm{~m}^{2} . \mathrm{K} / \mathrm{W}$, the minimum thickness of the foam should be equal to $80 \mathrm{~mm}$. A 3D scan of the surface acquired on a $300 \times 300 \mathrm{~mm}^{2}$ sample extracted from a larger wall (Figure 1-b) shows the classical aspect of a 3D printed surface obtained layer by layer. The measurement of the surface shows that the mean distance of the valley-peak is $15.7 \mathrm{~mm}$ with a standard deviation of $3.7 \mathrm{~mm}$. By a technique of picture autocorrelation, the space periodic analysis of the Foam 3D printed surface shows that the surface is periodic:

- In a vertical direction depending on the height of each foam layer

- In a horizontal direction, this periodic scheme can be explained by instabilities in the deposition as well as in the expansion of the foam.

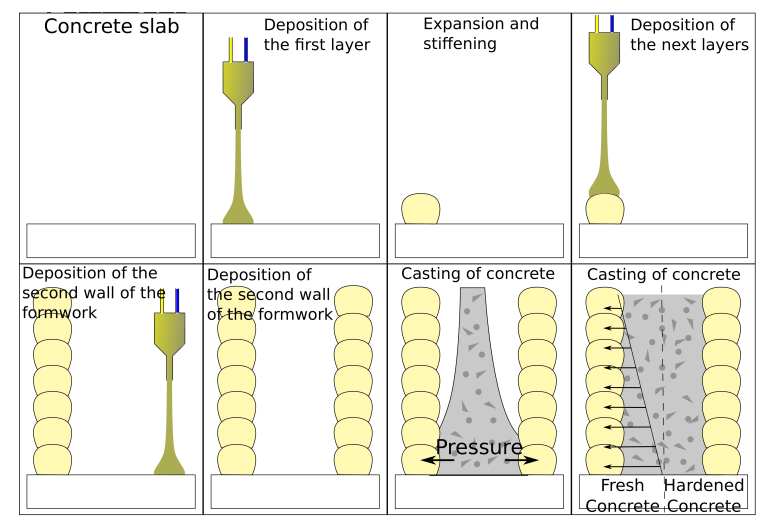

a)

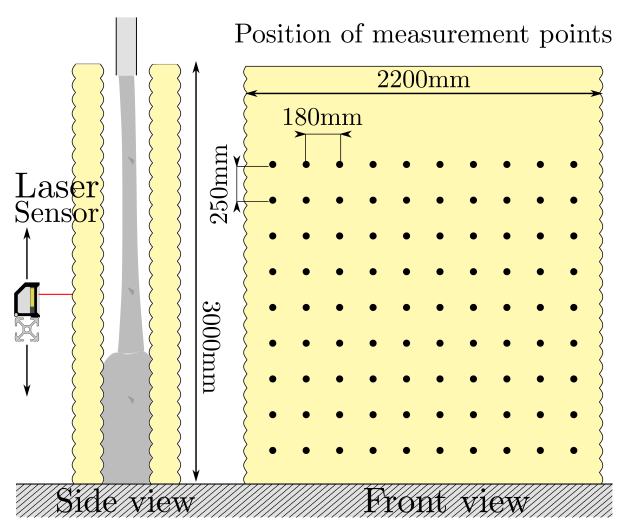

b)

Fig. 2 a) Phases for building the wall. b) Experimental device to analyze the FW deformations.

In order to comply with the construction standards or regulations, it must be ensured that during the construction of the concrete wall, the formwork must not be deformed by more than $5 \mathrm{~mm}$ for a height of $1 \mathrm{~m}$.

\subsection{Concrete characteristics}

The concrete is a self-compacting one (SCC) with a slump flow property $\mathrm{SF}=600 \mathrm{~mm}$. The concrete used for all the tests is composed of:

- cement CEM III 42.5

- limestone filler

- $\quad$ sand $(0-4 \mathrm{~mm})$

- gravel $(4-10 \mathrm{~mm})$

- water

- a set accelerator. 
With its composition, the concrete is directly pumped so that it flows easily into the printed FW without the need of vibration. The free surface obtained is horizontal. As the FW is made of an insulation material and because of the risk of the cure temperature of the concrete being too high which could create long term pathologies of the concrete and a shorter life time of the wall, the concrete is perfectly controlled with an adjusted set accelerator.

\subsection{Robotics system}

The robotic systems or machines that have been tested for different 3D building printing experiments in the world are, as explained by Labonnote in [6], based on two main principles: machines in the workshop to carry out the pre-manufacturing of elements or machines to build on site. In the case of building directly on the site, most of the experiments have been done with large gantry-type machines [9-15]. These types of machines require a lot of infrastructure and time and takes more time to assemble the gantry machine than to build a house [15, 24].

The solution proposed in this article is a robotic machine created especialy and composed of a mobile robot that will roll directly on the concrete slab made previously. This mobile robot carries a polyarticulated robot which prints the walls. The poly-articulated arm (PAA) is a standard industrial Staübli robot and the mobile one an Automatic Guided Vehicle (AGV) which is industrial as well but produced by BA Systèmes. With this mobile robot system, there is no specific infrastructure to plan and install on the construction site, like a crane or a portic, that will have to be dismantled once the house is built.

The PAA deposits the polyurethane foam and the concrete. It is carried by the AGV that can then move the PAA to different positions following the trajectories defined by the CAD-model or BIM of the house. Due to defaults in the flatness of the slab where the AGV rolls, the inaccurate positioning of the PAA is corrected in real time by measuring the spatial position of the AGV. A set of 11 fixed targets and a laser beam make up the guidance system of the AGV improved by using two embedded inclinometers. By matrix calculations, the position of the end-effector 3D printing is corrected in real time to compensate for the defects of the slab and provides an accuracy of $1 \mathrm{~mm}$ on the construction site $[25,26]$.

\subsection{Process}

As explained previously, for the Batiprint3DTM process, the robotics system needs to roll on the concrete slab that is made in advance. Thanks to the BIM, the geometry of the walls is known and all the reservations of the pre-equipment (arrivals and exits of fluids, arrivals of energies and networks, windows and doors etc.) and the steels for reinforcement of the construction are known by their designation and their position. With all this data, it's can be possible to create the trajectories for the displacements of the AGV and the 3D printing trajectories of the PAA. All this is done before starting the building directly in situ.

To begin the construction, the robot system is brought to the site and is placed on the concrete slab. There is also a pump for PU and another for concrete. The robot starts by printing the PU double skin around the house at an acceptable height to receive the concrete (between 40 and $110 \mathrm{~cm}$ ). The determination of the height depends of the foam formwork resistance to the hydrostatic thrust of the concrete. The determination method of the optimal height is presented in the next section. 
When the concrete mixer truck arrives, it transfers the fresh concrete into the pump that sends it to the effector of the robot that will be moved to print in the gaps between the walls of PU on the circumference of the House. The truck leaves and the robot resumes its work of making the PU formwork until the next truck arrives. When the required height of the walls is reached, the complete robot system rolls outside by a door that it has built.

The continuation of the house building can continue with external coatings as well as the application of the interior plaster. After this the following operations will be carried out: the wood frame and the roof, the installation of windows and doors, the electricity and the plumbing and the interior organization.

\subsection{Experimental devices}

The aim is to determine the deformations of the PU FW during the filling. In order to carry out these measurements, a Batiprint $3 \mathrm{D}^{\mathrm{TM}} \mathrm{FW}$ (height $3000 \mathrm{~mm}$, length $2500 \mathrm{~mm}$, width $80 \mathrm{~mm}+150 \mathrm{~mm}+$ $80 \mathrm{~mm}$ ) is 3D printed on a concrete slab and a framework composed of aluminium bars is mounted around the PU FW. One horizontal bar is equipped with 10 aligned laser sensors (Keyence IL-300) able to determine the distance between the sensors and the FW in the range [160mm; 440 mm], with a repeatability of $30 \mu \mathrm{m}$. The sensors are located according to the positions defined in Figure 2-b. Prior to the testing of the filling procedure with concrete, a filling test is carried out with water in order to determine the order of magnitude of the deformations with a purely hydrostatic pressure. The FW is filled from the bottom where a duct, equipped with a manometer, passes through the PU wall. Another transparent polyethylene tube is placed alongside the FW to check for the height of water. Different heights of water are tested. For each height of water, the bar equipped with the laser sensors is displaced at different heights and the distance between the sensors and the surface of the FW is measured. The deformation of the FW is obtained by subtracting this distance from the initial distance (empty FW).

The test is also performed on reinforced FW comprising spacers between the PU walls to limit the deformations. The number and the position of the spacers are determined by means of a finite element simulation. The concrete is delivered from the concrete plant by a concrete truck and the set accelerator is added on site. The concrete is mixed again for 10 minutes and is poured progressively into the concrete pump. It is then pumped to the nozzle. The inner diameter of the hose is $55 \mathrm{~mm}$ and its length is $20 \mathrm{~m}$. The nozzle is placed at the top of the FW and the concrete is cast from a height of $3 \mathrm{~m}$. The concrete is poured in 4 steps, at different heights [ $200 \mathrm{~mm} ; 500 \mathrm{~mm}$; $850 \mathrm{~mm} ; 1000 \mathrm{~mm}]$ and the deformations are measured.

\section{Results and discussions}

After performing the experiments the data was collected and Figures 3 and 4 present the deformation of the FW obtained in the different experimental tests.

\subsection{FW filled with water}

During the filling with water, the formwork exhibits significant deformations due to the hydrostatic pressure exerted by the water. This pressure depends on the height of water in the formwork. The deformations of the FW have initially been zeroed (blank map for a height of $0 \mathrm{~cm}$ ). The deformation maps show that the deformation is small when the height of water is low and increases for higher water heights. It can be possible to see that the FW is influenced by the increase in the height of water and that the deformations occur on the whole FW. The FW presents a maximum deformation 
at the centre because of its symmetric shape. Moreover, the point at which the deformation is the highest is located at approximately $50 \mathrm{~cm}$ from the slab. This deformation is equal to $10 \mathrm{~mm}$ for a height of water of $40 \mathrm{~cm}$ and can reach values as high as $25 \mathrm{~mm}$ for a height of $60 \mathrm{~cm}$. These deformations were visible to the naked eye.

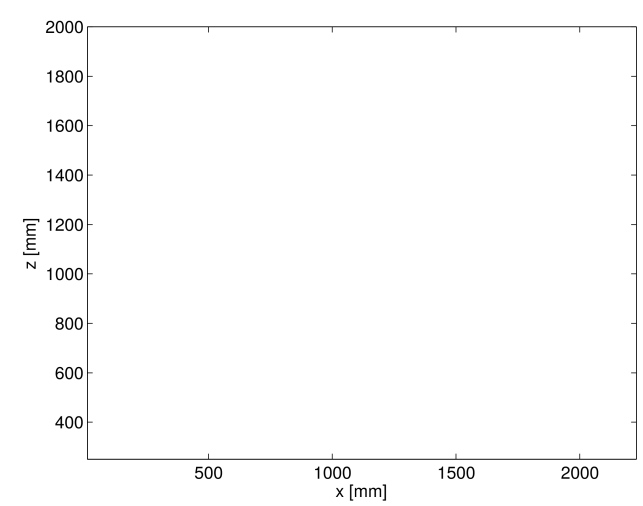

a) $0 \mathrm{~cm}$

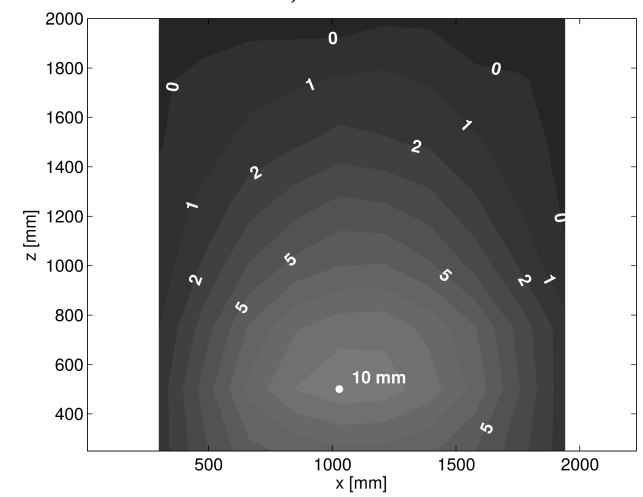

c) $40 \mathrm{~cm}$

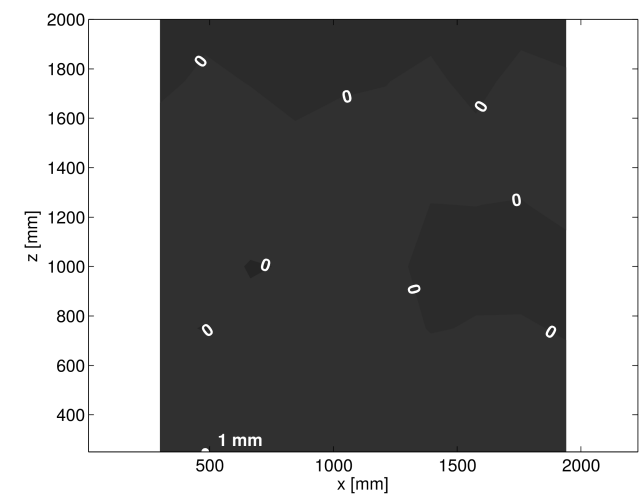

b) $20 \mathrm{~cm}$

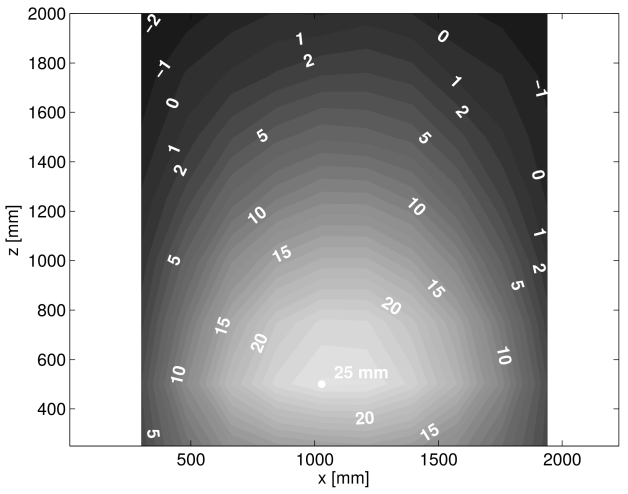

d) $60 \mathrm{~cm}$

Fig. 3 Deformations of the simple formwork for different heights of water (same color scale) - the numbers on each picture correspond to the deformation of the $\mathrm{FW}(\mathrm{mm})$ - the dot indicates the position and the value of the greatest deformation.

During the filling of the FW with water, water leaks were observed at certain locations. During the filling, crunches noices have been hear. For these reasons, it was decide not to fill the FW higher than $60 \mathrm{~cm}$, because of the risk of rupture. This test shows that it is not possible to fill the FW with water at full-height, a fortiori with concrete of greater density than water, and to maintain the deformations at values lower than $5 \mathrm{~mm}$. To solve this problem, it was decided to reinforce the FW with spacers, which maintain the distance between the two walls of the FW. The position of the spacers was first calculated by means of the Autodesk Robot Structural Analysis Professional software. The calculation was done by prescribing the mechanical properties of the PU foam and then applying the mechanical load assuming a purely hydrostatic pressure of the concrete. The computation of the deformations enabled us to place the spacers (considered as simple supports) by hand until deformations lower than $5 \mathrm{~mm}$ were obtained. Then the FW has been fill with water in the same manner as in the previous experiment. The results show that, in the present case, the deformations are limited to $4 \mathrm{~mm}$ for a height of $100 \mathrm{~cm}$, in compliance with the value of $5 \mathrm{~mm}$.

\subsection{Reinforced FW with concrete}

To check for the validity of the reinforcement positioning in the case of filling with concrete, a test is carried out on the same FW and with the same position of the spacers. The results are presented in Figure 4. During these tests, it's decide to fill the FW as high as possible, avoiding FW failure. The FW 
has been fill continuously, only stopping the pouring to measure the deformations. The selfcompacting concrete did not have enough time to stiffen and as a consequence, it imposed a standard hydrostatic pressure during the entire test.

The maximum deformation obtained is $20 \mathrm{~mm}$ for a height of concrete of $100 \mathrm{~cm}$. In order to avoid failure of the FW on the construction site and important losses of materials, the height of concrete that can be poured into the $F W$ must be lower than $50 \mathrm{~cm}$. As a consequence, the delivery of concrete must be planned by taking into account the time necessary to deposit a height of PU corresponding to the maximum height of concrete. For example, if the wall is $2.50 \mathrm{~m}$ high, it will be necessary to pour the concrete in 5 phases, each of which consists in the filling to a height of $50 \mathrm{~cm}$. Following this procedure will ensure the limitation of the deformations. Nevertheless, the fact that the concrete is poured in different phases implies that the cohesion between the different layers of concrete has to be evaluated. This has also been studied but is not presented here in this article.

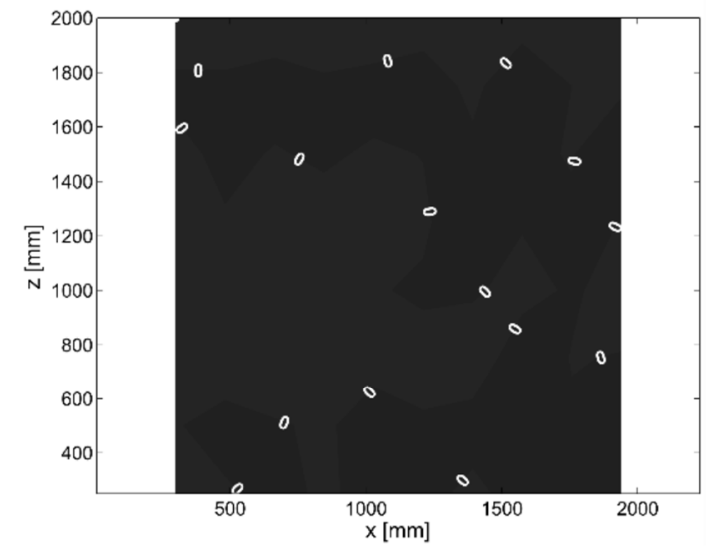

a) $20 \mathrm{~cm}$

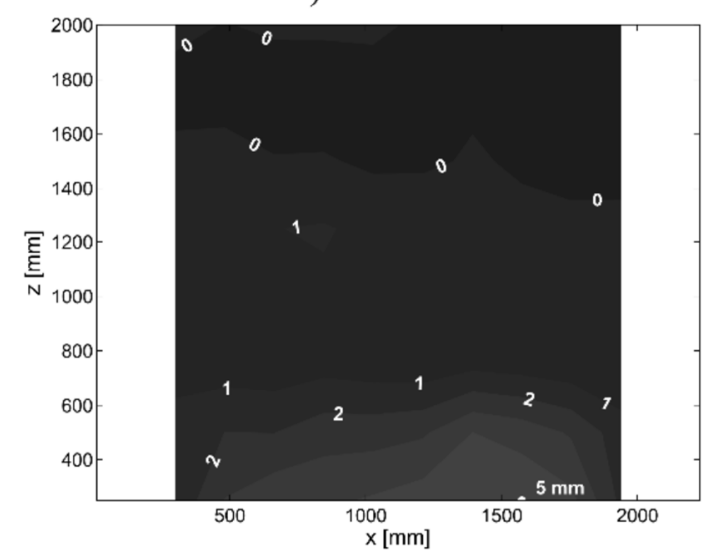

c) $85 \mathrm{~cm}$

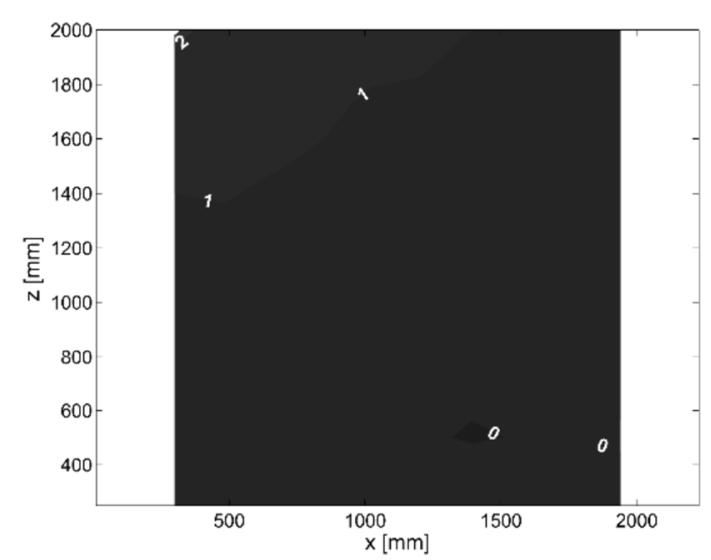

b) $50 \mathrm{~cm}$

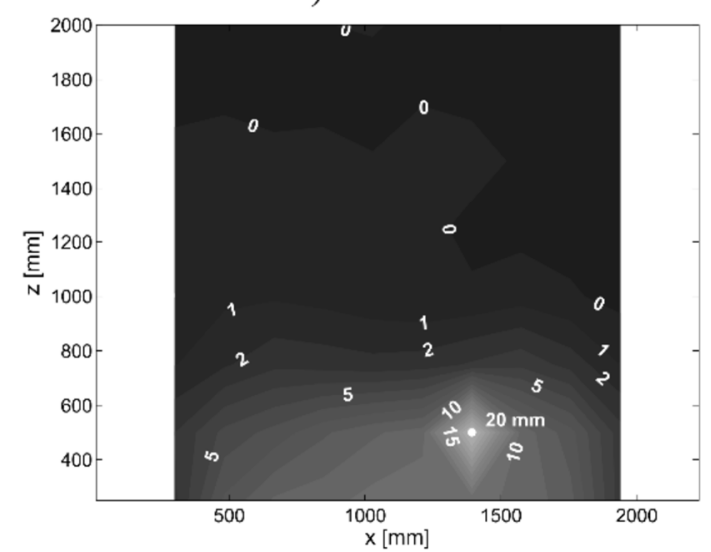

d) $100 \mathrm{~cm}$

Fig. 4 Deformations of the formwork for different heights of concrete (same color scale) - the numbers on each picture correspond to the deformation of the FW $(\mathrm{mm})$ - the dot indicates the position and the value of the deformation in $\mathrm{mm}$.

\section{Real scale demonstrator of 3D printing for building with Batiprint3 $\mathrm{D}^{\mathrm{TM}}$}

\section{1 $\quad$ Yhnova $^{\mathrm{TM}}$ social dwelling}

In September 2017, robotic 3D printing process Batiprint3D ${ }^{\mathrm{TM}}$ was used to build the walls of a real scale demonstrator: Yhnova ${ }^{\mathrm{TM}}$ (see Figure 5). This social dwelling is now owned by the landlord Nantes Metropole Habitat. The house is established in a classified wooded area and has the shape of a $\mathrm{Y}$ in order to not impinge on the roots of the trees or to cut their branches. Yhnova ${ }^{\mathrm{TM}}$ is a singlestory house with $95 \mathrm{~m}^{2}$ of living area with five rooms (four bedrooms + one living room). The total circumference is $55 \mathrm{~m}$. The height of the highest wall is $4.10 \mathrm{~m}$. The total wall surface to build was 165 
$\mathrm{m}^{2}$ (not including windows and doors). Taking into account the methodology presented in the previous section, eight steps were necessary to pour the concrete and maintain the deformations of the formworks at values lower than $5 \mathrm{~mm}$. To build the walls, the 3D Printer robot, developed in the university worked for 54 hours. The time between two pourings of concrete was greater than 7 hours. This time was necessary to let the concrete stiffen and maintain the upper layers, even if the short setting time obtained, thanks to the set accelerator, enabled an increased pouring rate. During this time the robot continued printing the foam FW. During the construction, the deformations of the FW after each concrete pouring have been checked. The verticality of the walls on all the height has been controled. No deviation from the predicted deformations was observed, which validated the procedure.

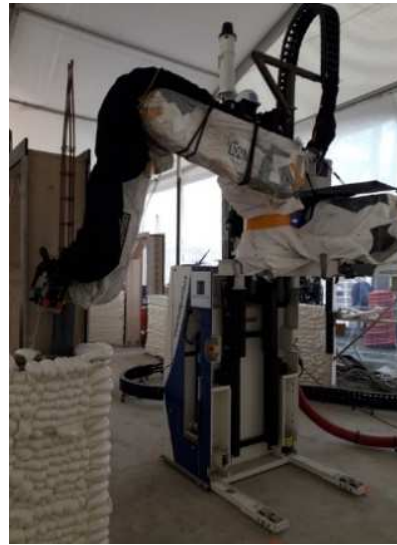

a)

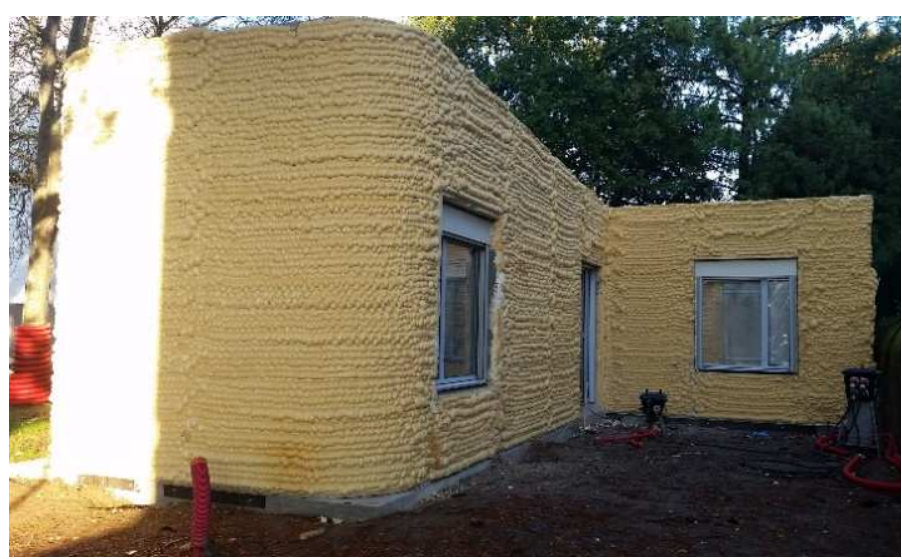

b)

Fig. 5 a) Robots at work (AGV+PAA). - b) Picture of Yhnova ${ }^{\mathrm{TM}}$ without coating.

\subsection{Synthesis of impacts of this new advanced technology for building construction}

The construction leveages the possibilities offered by the BatiPrint3 $3 \mathrm{D}^{\mathrm{TM}}$ construction principle so that the house could have large curved shapes following the available space and the openings are positioned to avoid visual constraints and thus enable the tenants to enjoy the view of the garden and trees. Coupled with its reliability and insulation, its curves make this housing concept both modern and traditional. The house is perfectly integrated into its surroundings and the building process totally respects the environment (see Figure 6). The thermal performances achieved by the walls are 30 to $40 \%$ higher than the best standards practiced in current traditional construction, according to the French regulations regarding building environmental performances (RT2012).

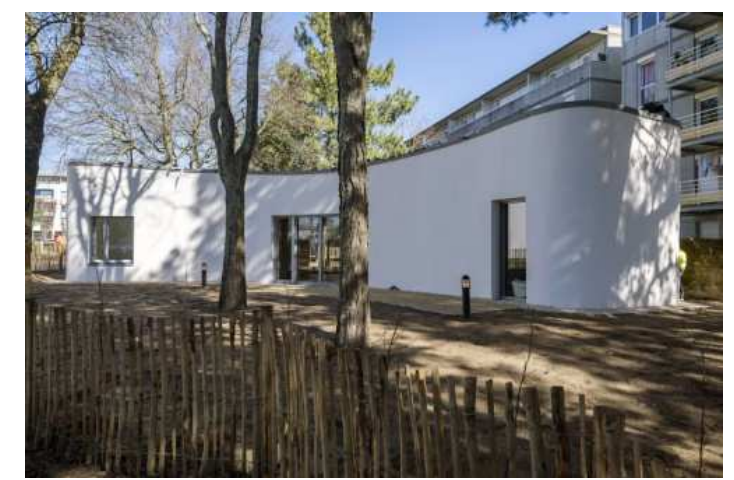

Fig. 6 a) The finished social housing.

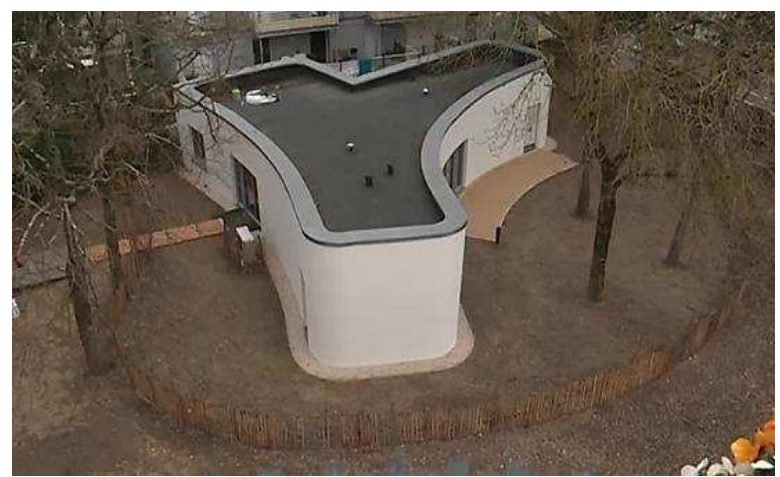

b) YhnovaTM in its environment. 
The assessment below details the construction principles of BatiPrint3 $\mathrm{D}^{\mathrm{TM}} \mathrm{s}$ robotic $3 \mathrm{D}$ printing as applied to the construction of $\mathrm{Yhnova}^{\mathrm{TM}}$ :

- The construction sector in France is known for high number of work accidents or musculoskeletal disorders due to on site high level work, required moving of heavy loads, the use of high power machines, repetitive tasks etc. One advantage of BatiPrint $3 D^{T M}$ is that the work is less strenuous and the risks of work accidents during the shell construction phase decrease: no scaffolding onsite and as a result no need for employees to move up and down, no loads to carry, less hard work.

- For several years the French construction sector has suffered from a severe labor shortage due to the strenuous nature of the job for onsite workers and to the feeling that onsite jobs are unskilled and low-paid. Such a construction process relying on digital and robotic technologies brings a very positive image to the building and construction sector, especially among young people, which could help the companies to recruit new types of skilled workers and counter the labor shortage.

- $\quad$ - There is a positive evolution in the building trades similar to that experienced by the manufacturing industry. Traditionnal building is therefore moving towards the "construction site of the future". This means that new workers will be needed with different skills than those usually needed on a construction site. It also means that the use of digital and robotic technologies on the construction site could help to improve the construction tolerances and to better manage the site. Furthermore, improved tolerances for the building structure construction are better for the work of the subcontractors for roofs, doors, windows etc.

- Thanks to the swiftness of execution, human dependence on weather conditions is lower than in traditional construction (the process is very fast, 50 hours to build $100 \mathrm{~m}^{2}$ ).

- The entire digital chain, from drawing the house to construction is totally integrated: from the design of the plans on a computer to manufacturing by the robot; this makes it possible to virtually validate the design of the house so that the robot immediately creates the desired shapes. Moreover, the use of robots onsite requires knowing the exact positions of the different networks in the building (electricity, drinkable water, waste water, heating, ventilation, air conditioning etc.), and the positions of the reinforcement bars and the joinery, that is why the BIM (Building Information Model) is essential to better prepare the trajectories of the robots and the deposition paths.

- The principle and the systems in place reduce the cost of the shell construction by around $20 \%$ compared to the cost of traditional methods (masonry blocks) involving insulated walls with the same shape and same insulation performances. This is particularly due to the fact that both the structure of the building and the insulation are deposited at the same time. This is also due to the increase in the cost of construction with traditional methods when building curved walls.

- The energy performance of the house was improved well beyond current standards. According to the French regulations concerning energy consumption (RT2012), the yearly consumption of primary energy $C_{\mathrm{ep}}$ must be lower than $50 \mathrm{kWh} / \mathrm{m} / \mathrm{m}^{2}$ and the bioclimatic needs Bbio must be lower than 60 . For Yhnova ${ }^{\mathrm{TM}}, \mathrm{Cep}=33.1 \mathrm{kWh} / \mathrm{m}^{2}$.year and $B b i o=34.2$, shows a reduction of 30 to $40 \%$. This reduction is due to the thickness of insulation material, but also to the optimized shape of the building that reduced the coefficient of thermal bridges in the curved angles of the house. Indeed, a curved angle with such a radius of curvature does not disturb the isothermal surfaces inside the wall and no cold points appear on the inner surface of the wall or hot points on the outer surface.

- The principle and the printer robot enable greater freedom of shape for buildings which are more adapted and perfectly suited to human needs (curves, smooth corner, external forms, indoor atmosphere etc.). 
- The Batiprint3D $\mathrm{D}^{\mathrm{TM}}$ process reduces the environmental impact (direct use of raw materials, the absence of waste, reduced transportation, and minimization of energy use etc.). To insulate the whole YhnovaTM house, only 4 barrels of PU, carried onsite with a simple delivery van, were needed. No environmental studies or life cycle assessments have been carried out to date but will be done over the next few months. It can be notice that the fact of reducing the number of trucks, the direct use of raw materials and the absence of waste all contribute to the lowering of environmental impacts.

\section{Conclusion}

Batiprint $3 \mathrm{D}^{\mathrm{TM}}$ is a technique of additive manufacturing based on the $3 \mathrm{D}$ printing of polyurethane foam to make a formwork in which concrete is cast by the same robotic 3D printer. The structure of the building is of concrete and its insulation is obtained by the formwork kept in place.

The on-site implementation of the technique requires carrying out preliminary experiments in order to calculate the optimal parameters for the printing process. In particular, a suitable procedure for the filling of the FW with self-compacting concrete has been determined. Thus, the FW deformations during the filling have been measured by laser sensors in order to obtain deformation maps of the FW. The filling with water and concrete enabled to validate the filling procedure that limited the deformations to values lower than $5 \mathrm{~mm}$. In September 2017, this technique was implemented on site to build a YHNOVA ${ }^{\mathrm{TM}}$ dwelling in only 54 hours. During the construction, the deformations have been controled and remained lower than $5 \mathrm{~mm}$.

This house is located in Nantes (France) and has a surface area of $95 \mathrm{~m}^{2}$. It is completely finished and belongs to Nantes Metropole Habitat. This house has been occupied by a family since June 2018 and its use, in terms of comfort and pleasure, is very appreciated by its inhabitants.

This current research work is looking at how to improve the 3D printing robotic system for the construction of two-storey housing. This new technique highlights a new perspective for this sector and is a promising solution. Still using Batiprint3 $\mathrm{D}^{\mathrm{TM}}$ technology, it can be possible testing to print more complex shapes such as roofs or ceilings. Future constructions are being contemplated such as a large commercial mall of $700 \mathrm{~m}^{2}$ using complex shapes and a group of 21 houses in a isle in an hurricane zone. Finally, for the future, new research can be conducted with 3D printing tests of earth or clay to build more sustainable homes.

\section{Acknowledgment}

The authors would like to thank the project partners of Batiprint $3 \mathrm{D}^{\mathrm{TM}}$ technology and the YHNOVA ${ }^{\mathrm{TM}}$ house: Caisse des Depots, Nantes Metropole, SATT Ouest Valorisation, Nantes Metropole Habitat, TICA Architecture and the project research engineers, Elodie Paquet, Laurence Guiheneuf, Nicolas Houssais and Thomas Bressac.

\section{References}

[1] F2792-12a - standard terminology for additive manufacturing technologies. ASTM International, 2013

[2] Bradley H. Jared, Miguel A. Aguilo, Lauren L. Beghini, Brad L. Boyce, Brett W. Clark, Adam Cook, Bryan J. Kaehr, and Joshua Robbins. Additive manufacturing: Toward holistic design. Scripta Materialia, 135:141 - 147, 2017. ISSN 1359-6462

[3] T. Friedman. When complexity is free. The New York Times, 2013 
[4] Imane Krimi, Zoubeir Lafhaj, and Laure Ducoulombier. Prospective study on the integration of additive manufacturing to building industry-case of a french construction company. Additive Manufacturing, 16:107-114, 2017

[5] Izabela Hager, Anna Golonka, and Roman Putanowicz. 3D printing of buildings and building components as the future of sustainable construction? Procedia Engineering, 151:292 - 299, 2016

[6] Nathalie Labonnote, Anders Rønnquist, Bendik Manum, and Petra Rüther. Additive construction: State-of-the-art, challenges and opportunities. Automation in Construction, 72:347366, 2016

[7] Ph. Poullain, B. Furet, E. Paquet, and S. Garnier. Batiprint and yhnova : Open innovation projects in the context of large scale additive manufacturing. In ACE Workshop - Lille 2017, 2017

[8] C. Gosselin, R. Duballet, Ph. Roux, N.Gaudillière, J. Dirrenberger, and Ph. Morel. Large-scale $3 \mathrm{~d}$ printing of ultra-high performance concrete - a new processing route for architects and builders. Materials and designs, 100:102-109, 2016

[9] Contour crafting - http://contourcrafting.com/, 2018

[10] Behrokh Khoshnevis. Automated construction by contour crafting-related robotics and information technologies. Automation in Construction, 13(1):5-19, 2004

[11] Jing Zhang and Behrokh Khoshnevis. Optimal machine operation planning for construction by contour crafting. Automation in Construction, 29:50-67, 2013

[12] Win sun - http://www.yhbm.com/, 2018. URL http://www.yhbm.com/

[13] Loughborough university - http://www.lboro.ac.uk/enterprise/case-studies/3d-concreteprinting/, 2018. URL http://www.lboro.ac.uk/enterprise/case-studies/3d-concrete-printing/

[14] S. Lim, R.A. Buswell, T.T. Le, S.A. Austin, A.G.F. Gibb, and T. Thorpe. Developments in construction-scale additive manufacturing processes. Automation in Construction, 21:262 - 268, 2012

[15] D-shape - https://d-shape.com/, 2018. URL https://d-shape.com/

[16] 3d-construction - https://www.constructions-3d.com/, 2018

[17] Xtreee the large scale 3d-http://www.xtreee.eu/, 2018

[18] Apis cor - we print buildings - http://apis-cor.com/en/, 2018

[19] Batiprint3d-http://www.batiprint3d.fr, 2018

[20] Total kustom - http://www.totalkustom.com/, 2018

[21] MIT - http://news.mit.edu/2017/3-d-printing-buildings-0426

[22] Cybe - https://www.cybe.eu, 2018

[23] Bet abram - betabram.com, 2018

[24] 3dprinthuset - https://3dprinthuset.dk, 2018 
[25] Sébastien Garnier, Kévin Subrin, Pablo Arevalo-Siles, Guy Caverot, Benoit Furet, "Mobile robot stability for complex tasks in naval industries", 51st CIRP Conference on Manufacturing Systems 2018.

[26] Kevin Subrin, Thomas Bressac, Sebastien Garnier, Alexandre Ambiehl, Elodie Paquet, Benoit Furet, "Improvement of the mobile robot location dedicated for habitable house construction by 3D printing", INCOM2018. 